\title{
All fiber based supercontinuum light source utilized for IR microscopy
}

Dupont, Sune ; Petersen, Christian ; Thøgersen, Jan; Agger, Christian; Bang, Ole; Keiding, Søren Rud

Published in:

CLEO Technical Digest

Publication date:

2012

Document Version

Publisher's PDF, also known as Version of record

Link back to DTU Orbit

Citation (APA):

Dupont, S., Petersen, C., Thøgersen, J., Agger, C., Bang, O., \& Keiding, S. R. (2012). All fiber based supercontinuum light source utilized for IR microscopy. In CLEO Technical Digest (pp. JW4A.64). Optical Society of America.

\section{General rights}

Copyright and moral rights for the publications made accessible in the public portal are retained by the authors and/or other copyright owners and it is a condition of accessing publications that users recognise and abide by the legal requirements associated with these rights.

- Users may download and print one copy of any publication from the public portal for the purpose of private study or research.

- You may not further distribute the material or use it for any profit-making activity or commercial gain

- You may freely distribute the URL identifying the publication in the public portal

If you believe that this document breaches copyright please contact us providing details, and we will remove access to the work immediately and investigate your claim. 


\title{
All fiber based supercontinuum light source utilized for IR microscopy
}

\author{
Sune Dupont ${ }^{1}$, Christian Petersen ${ }^{2}$, Jan Thøgersen $^{2}$, Christian Agger $^{3}$, Ole Bang $^{3}$, and \\ Søren Rud Keiding ${ }^{2, *}$ \\ ${ }^{1}$ Department of Physics and Astronomy, Aarhus University, DK-8000 Aarhus C, Denmark \\ ${ }^{2}$ Department of Chemistry, Aarhus University, DK-8000 Aarhus C, Denmark \\ ${ }^{3}$ DTU Fotonik, Department of Photonics Engineering, Tech. Uni. of Denmark, DK-2800 Kgs. Lyngby, Denmark \\ *keiding@chem.au.dk
}

\begin{abstract}
An all fiber based supercontinuum light source is demonstrated for infrared microscopy. The high brightness and spatial coherence of the source facilitate fast high resolution measurements.

(C) 2011 Optical Society of America

OCIS codes: (180.0180) Microscopy, (320.6629) Supercontinuum generation
\end{abstract}

Infrared microscopy combines the selectivity of a spectrometer with the spatial resolution of a microscope and is utilized in a wealth of applications from forensic science to sustainable energy research [1]. High resolution infrared (IR) microscopy requires intense and spatial coherent sources of infrared radiation [2]. However, most IR microscopes are based on thermal IR sources with very low brightness and is therefore not suitable for high resolution measurements. Here we present an all fiber based supercontinuum (SC) light source used for IR microscopy.

The IR source is based on SC generation in an optical fiber. In the SC process the spectral width of a laser pulse widens from a few nanometers to several optical octaves [3,4]. SC generation has been known for decades and has led to several breakthroughs in spectroscopy and imaging [5,6]. Recently, the supercontinuum technique was extended to the infrared spectral range beyond $2.6 \mu \mathrm{m}$, by applying soft glass materials such as ZBLAN [7]. The spectral brightness of the infrared SC is several orders of magnitude higher than that of a thermal infrared source and since the $\mathrm{SC}$ is generated in a single fiber-mode the light has a high spatial coherence. This makes IR SC ideal for IR microscopy where a high brightness is desired.

A schematic overview of the microscope setup is seen in Figure 1a. The light source is a ZBLAN fiber, pumped by a $40 \mathrm{MHz}$ fiber-laser emitting $1 \mathrm{ps}$ pulses at $1900 \mathrm{~nm}$ with a pulse energy of $16 \mathrm{~nJ}$. The generated IR SC is seen in Figure 1b. The SC output from the fiber is collimated and refocused using aspherical ZnSe lenses. In the focus a sample is held between two $\mathrm{CaF}_{2}$ windows. The light dispersed by the sample is measured by a monochromator equipped with a PbSe detector. Raster scanning the sample provides a spectral absorption image at one wavelength.

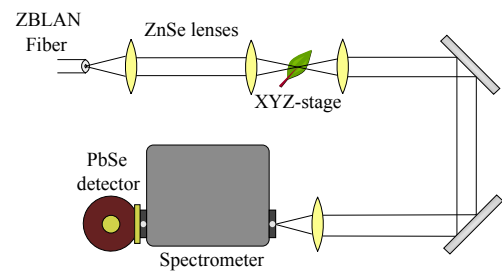

(a)

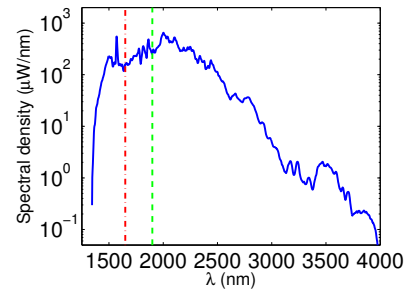

(b)

Fig. 1: 1a The IR microscope. 1b The output spectrum from the SC source.

The chemical resolution of the microscope is investigated with a pure oil sample. An absorption spectrum is obtained by scanning the monochromator. In Figure $2 \mathrm{a}$ the acquired spectrum is compared with a FTIR measurement of the same sample and a fine agreement is seen. The chemical selectivity is investigated with a sample consisting of an oil/water mixture. An optical microscope image of the sample shown in Figure 2b. There are three regions in the image, but they cannot be distinguished. The images in Figure $2 \mathrm{c}$ and $2 \mathrm{~d}$ are IR absorption images made by raster 
scanning the sample in steps of $5 \mu \mathrm{m}$. This is done at two wavelengths corresponding to high absorption in water and oil respectively. Blue parts of the images indicate high absorption, and red parts low absorption. Figure 2c displays the absorption in water at $3.05 \mu \mathrm{m}$. A high absorption is clearly seen in the upper part of the picture and points to the presence of water in this region. Figure $2 \mathrm{~d}$ displays the absorption in oil at $3.5 \mu \mathrm{m}$. Here we see high absorption in the lower part, some absorption in the upper part and low absorption in the central part. The high absorption in the lower part indicates that this is oil. The upper part shows some absorption and come from the tail of absorption in water at long wavelengths. The central part shows low absorption in both pictures and corresponds to an air bubble trapped at the interface. It is seen that more information is gained from the IR images than from a normal optical image.

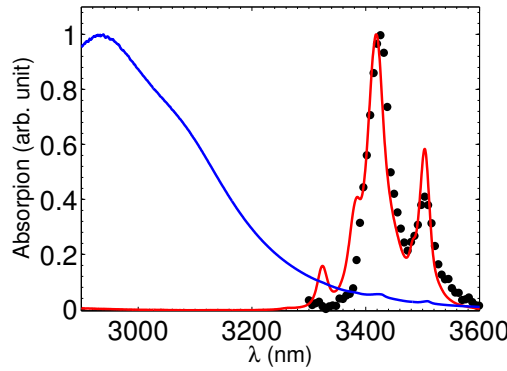

(a)

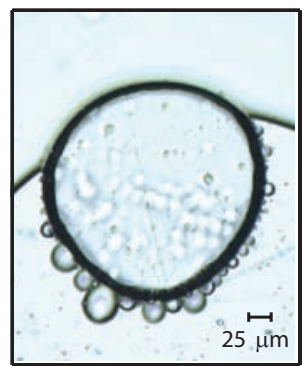

(b)

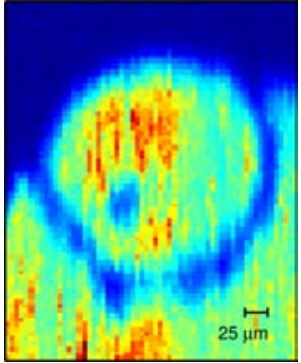

(c)

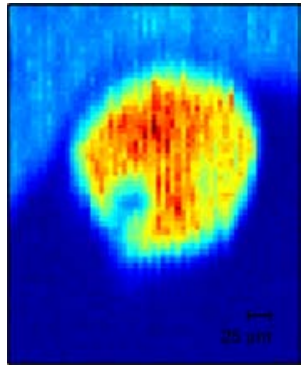

(d)

Fig. 2: (a) Blue and red lines: FTIR absorption spectra of water and oil respectively. Dots: Oil absorption measured with SC source. (b) Optical microscope image of the sample. (c) and (d) IR images of sample measured at $3.05 \mu \mathrm{m}$ and $3.50 \mu \mathrm{m}$ corresponding to wavelengths of high water absorption and high oil absorption, respectively. The blue color indicates high absorption and the red low absorption. The image size is $300 \times 375 \mu \mathrm{m}^{2}$ and each pixel is $5 \times 5 \mu \mathrm{m}^{2}$.

The fiber based SC has a high spatial coherence and enable, in principle, diffraction limited measurements. The spatial resolution in our demonstration setup is determined by the spot size of the light. This is measured at three different wavelengths with the knife edge method. The combined minimum beam radius has a minimum of $17 \mu \mathrm{m}$. The ability to focus the fiber based SC source to a small spot is crucial, as it provides a significantly higher brightness than provided by thermal sources. This enables faster raster scanning in high spatial resolution measurements.

In conclusion, we have demonstrated that an infrared supercontinuum source based on an optically pumped ZBLAN fiber provides a simple, bright and broadband light source ideally suited for high resolution infrared microscopy. Even this proof of principle setup allows us to obtain images with a good spatial resolution, and with chemical selectivity, based on the selective absorption of the infrared light by the different molecules in the sample.

\section{References}

1. H. Humecki, Practical Applications of Infrared Microspectroscopy (Marcel Dekker, Inc., New York, 1995).

2. L. M. Miller and R. J. Smith, "Synchrotrons versus globars, point-detectors versus focal plane arrays: Selecting the best source and detector for specific infrared microspectroscopy and imaging applications," Vib. Spec. 38, 237-240 (2005).

3. R. R. Alfano and S. L. Shapiro, "Emission in region 4000 to 7000 å via 4-photon coupling in glass," Phys. Rev. Lett. 24, 584-586 (1970).

4. H. Imam, "Broad as a lamp, bright as a laser," Nature Photonics 2, 26-28 (2008).

5. S. A. Diddams, D. J. Jones, J. Ye, J. L. Hall, J. K. Ranka, R. S. Windeler, R. Holzwarth, T. Udem, and T. W. Hänsch, "Direct link between microwave and optical frequencies with a $300 \mathrm{THz}$ femtosecond laser comb," Phys. Rev. Lett. 84, 5102-5105 (2000).

6. H. N. Paulsen, K. M. Hillingsø, J. Thøgersen, S. R. Keiding, and J. J. Larsen, "Coherent anti-stokes raman scattering microscopy with a photonic crystal fiber based light source," Optics Letters 28, 1123-1125 (2003).

7. C. Xia, M. Kumar, O. P. Kulkarni, M. N. Islam, F. L. Terry, Jr., M. J. Freeman, M. Poulain, and G. Maze, "Mid-infrared supercontinuum generation to $4.5 \mu \mathrm{m}$ in zblan fluoride fibers by nanosecond diode pumping," Opt. Lett. 31, 2553-2555 (2006). 